\title{
Self-punitive behavior: Nonreinforcement procedure of extinction
}

\author{
R. CHRIS MARTIN, D. WAYNE MITCHELL, and CARL J. ROGERS \\ University of Missouri, Kansas City, Missouri 64110
}

\begin{abstract}
Two groups of rats were given escape training in an automated double runway. During a nonreinforcement procedure of extinction (no shock offset in the goal/startboxes), punishment was introduced to one group by increasing the alleyways' shock intensity above that of the goal/startboxes. The other group was not punished. The results revealed that the punished group was more resistant to extinction. This finding enables a more direct comparison of results obtained under appetitive and aversive motivation conditions and supports the need for a motivational factor split.
\end{abstract}

Self-punitive behavior (SPB) describes a condition in which punishment of a conditioned escape or avoidance response maintains or enhances the response relative to nonpunished subjects (Brown, 1969; Melvin, 1971; Martin, Note 1). All SPB investigations previously conducted used a drive-shift extinction procedure, that is, no shock. In contrast, most appetitive motivation studies used a nonreinforcement extinction procedure, that is, removal of a food pellet. The nonreinforcement procedure results in the maintenance of the primary drive state during extinction. The no-shock procedure, however, results in the complete reduction of the primary drive state. The appropriate aversive analogy to the nonreinforcement procedure thus is no shock offset.

Implementation of the extinction procedure of no shock offset has, however, proved to be a tactical problem. This problem stems from the fact that in single alleyways, even if the subject is given no shock offset upon reaching the goalbox, shock offset inevitably occurs when the animal is returned to the startbox for the ensuing trial. A method to correct this problem is the use of an automated double runway. This apparatus circumvents the necessity for handling the animal once the experiment has begun.

The question of whether different laws of behavior are in operation when an organism is operating under aversive motivation as opposed to appetitive motivation has received considerable attention (Martin, Note 2). One of the areas suggested for investigation of possible differential effects due to the type of motivation is the treatment condition of punishment.

The objectives of this study were twofold: (1) to determine whether the SPB would be found in a nonreinforcement procedure of extinction, and (2) to enable a more direct comparison between the effects of punishment upon appetitively and aversively motivated behavior.

\section{METHOD}

\section{Subjects}

The subjects were 24 male albino rats obtained from Sasco Company. They were approximately 90 to 120 days old and weighed approximately $200 \mathrm{~g}$. Subjects were individually housed and were maintained on an ad-lib diet of food and water under a 12 -h light-dark cycle.

\section{Apparatus}

The apparatus was an automated double runway with connecting goal/startboxes. The complete apparatus was encased by a sound-resistant box made of $1.9-\mathrm{cm}$ plywood painted white on the inside. The runways were separated from the goal/startboxes by hinged doors operated by $110-\mathrm{V}$ ac reversible motors. The dimensions of the alleys were 24.13 (H) $\times 15.24$ (W) $\times 168 \mathrm{~cm}(\mathrm{~L})$. The dimensions of the goal/ startboxes were $24.13(\mathrm{H}) \times 29.21$ (W) $\times 15.24 \mathrm{~cm}(\mathrm{~L})$. The walls were $.63-\mathrm{cm}$ white opaque Plexiglas throughout the apparatus. Hinged tops of $.63-\mathrm{cm}$ clear Plexiglas covered both the runways and goal/startboxes. The floor consisted of $.33-\mathrm{cm}$ stainless steel rods spaced $.95 \mathrm{~cm}$ apart. Start time was the time from the opening of the alley doors until the first photocell was passed $(29.21 \mathrm{~cm})$ down the alley. Alley time was recorded as the time between the passing of the first photocell and the second photocell, $116.84 \mathrm{~cm}$ apart. The latencies were recorded on a Coulbourn Instruments printout counter. Intertrial intervals (ITI), door openings, and lights were controlled by associated electronic components. The shock sources were three Lehigh Valley constant-current shockers. Each shock source measured $900 \mathrm{~V}$ at $2 \mathrm{~mA}$ with a test resistor in the circuit. All programming and recording devices were placed in an adjacent room to isolate the subjects from extraneous noise.

\section{Procedure}

All subjects received the same pretraining and training procedures. Pretraining consisted of four escape shaping trials. During the first two pretraining trials, the alley was blocked by a clear Plexiglas barricade temporarily placed approximately $30 \mathrm{~cm}$ from the goalbox (GB) door. The subject was placed between the barricade and the GB. Within $60 \mathrm{sec}$, the grid was electrified with 2-mA shock and the GB door simultaneously opened. Subjects escaped to the nonelectrified GB. This procedure was repeated in the second alley. During the next two pretraining trials, the Plexiglas barricade was placed in the alley approximately midway between the start- and goalbox doors. 
The subject was placed into the appropriate alley and the pretraining procedure repeated in both alleys. At the end of the last pretraining trial, the subject remained in the GB, which now served as the startbox (SB) for the first training trial. The barricades were removed and 35 training trials begun with a 60-sec ITI. The 35 training trials each consisted of the SB and alley electrified at $2 \mathrm{~mA}$, with the GB being safe (no shock). SB latencies and alley speeds were recorded. No handling of the subjects occurred after the pretraining was completed.

Testing began immediately after training. Subjects received one of two conditions: The nonpunished group received no offset of a 2-mA shock in the GB; the punished group also received no offset of a $2-\mathrm{mA}$ shock in the GB, though the alley shock for the punished group was raised to $2.75 \mathrm{~mA}$. During the 60 -sec ITI, all subjects were continuously shocked. SB latencies and alley speeds were recorded. Animals in both groups were run until they met criterion for extinction (90 sec before reaching the GB or 70 trials, whichever occurred first). Number of trials to extinction was recorded for each subject.

\section{RESULTS}

The two groups did not differ during acquisition, as shown by $t$ tests of the last block of six trials for both the punished and nonpunished groups.

The alley speed data for both groups during testing are shown in Figure 1. It may be seen that the punished group ran faster and persisted longer than did the nonpunished group. This result was supported by an analysis of variance of the alley speeds across 39 trials of testing: punished conditions $[\mathrm{F}(1,22)=26.81, \mathrm{p}<.001]$, trials $[F(12,262)=20.21, \mathrm{p}<.001]$, and Punishment by Trials interaction $[F(12,262)=2.85, p<.001]$.

Figure 2 summarizes the startbox speed data for the punished and nonpunished groups. Escape responses of the punished group are shown to be more persistent and faster than those of the nonpunished group. An analysis of variance of startbox speeds across 39 trials in the testing phase showed punishment conditions $[F(1,22)=29.75, p<.001]$, trials $[F(12,264)=11.59$, $\mathrm{p}<.001]$, and the Punished Conditions by Trials interaction $[F(12,264)=2.56, p<.001]$ to be significant.

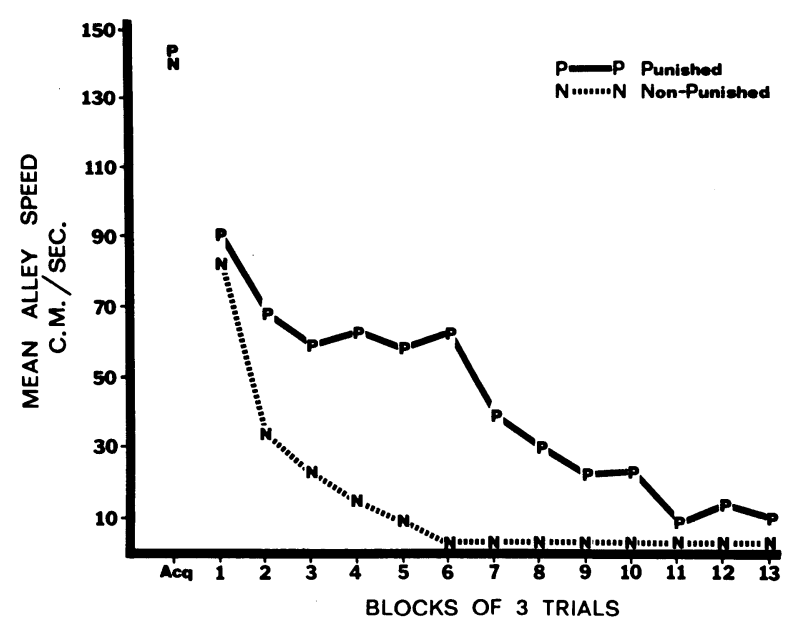

Figure 1.

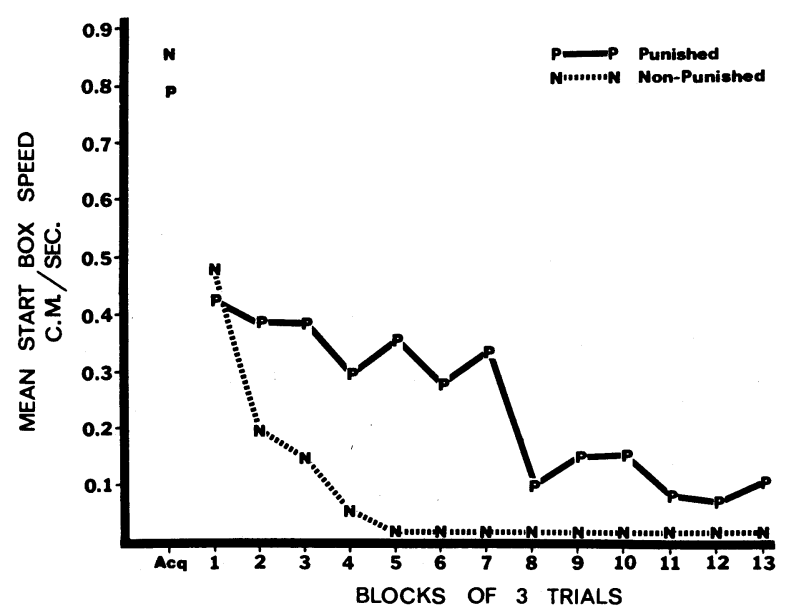

Figure 2.

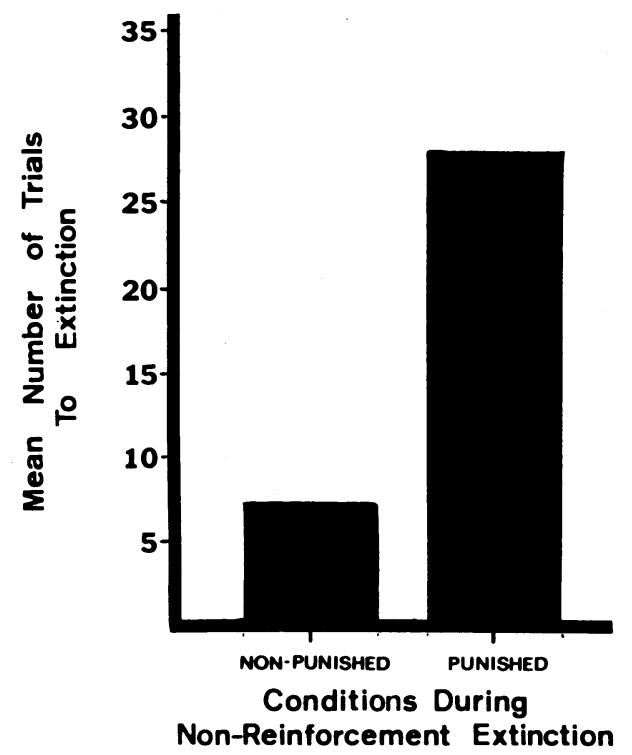

Figure 3.

The mean number of trials to extinction for the punished and nonpunished groups are shown in Figure 3. The punished group was more resistant to extinction than the nonpunished group. A Kruskal Wallis one-way analysis of variance $[(\mathrm{H} 91)=16.8, \mathrm{p}<.001]$ showed the difference to be significant.

\section{DISCUSSION}

The persistent effects of SPB were demonstrated by the faster startbox and alley speeds as well as the greater number of trials to extinction for the punished group. The punished group showed a gradual decrease in running speed, whereas the nonpunished group showed an immediate reduction in running speed, a typical difference found between punished and nonpunished subjects (Brown, Martin, \& Morrow, 1964). While the punished group revealed significantly stronger resistance to extinction than the nonpunished group, it might be noted that the absolute level of resistance to extinction of the punished group was only about 40 trials, less than that typically 
reported in the drive-reduction extinction procedure experiments.

The facilitative effect of punishment has been argued to be a function of the dependent measure used. Delude (1969), for example, found no significant difference between punished and nonpunished conditions when startbox latency was used as a measure of SPB. In the present experiment, SPB was shown with both startbox speed and trials-to-extinction measures, contradicting the argument proposed by Delude.

Dreyer and Renner (1971) resurrected the discrimination hypothesis as an explanation of SPB by stating, "The rate of extinction should be influenced only by changes which do in fact affect a discrimination between shock and non-shock in the start box" (p. 333). In the present experiment, both the punished and nonpunished subjects received the same levels of shock in the startbox during extinction. By the logic proposed by Dreyer and Renner, both groups should have stopped responding after an equal number of trials. The present results showed differential responding.

The data acquired in this study are consistent with the Mowrer-Brown theoretical explanation which emphasizes the level of motivation in the startbox (usually fear) for initiation of the response. Running, since it results in a punished response followed by reduction in intensity of shock, is thus reinforced. Since only the punished group received any such reinforcement, these results reveal that offset or reduction of shock intensity alone may be sufficient to maintain SPB.

In conclusion, the fact that punishment of aversively motivated subjects produced SPB even with a nonreinforcement procedure of extinction, while punishment of appetitively motivated subjects typically suppressed responses, provides strong support for the contention that the quality of motivation (appetitive vs. aversive) merits serious consideration in the analysis of behavior.

\section{REFERENCE NOTES}

1. Martin, R. C. Resistence to extinction of an escape response as a function of number of reinforcements. Unpublished doctoral thesis, University of Florida, 1964.

2. Martin, R. C. The quality of motivation. Paper presented at the meeting of the Midwestern Psychological Association, Chicago, 1975.

\section{REFERENCES}

Brown, J. S. Factors affecting self-punitive behavior. In B. Campbell \& R. M. Church (Eds.), Punishment and aversive behavior. New York: Appleton-Century-Crofts, 1969.

Brown, J. S., Martin, C. C., \& Morrow, M. W. Self-punitive behavior in the rat: Facilitative effects of punishment on resistance to extinction. Journal of Comparative and Physiological Psychology, 1964, 57, 127-133.

Delude, L. A. The vicious circle phenomenon: A result of measurement artifact. Journal of Comparative and Physiological Psychology, 1969, 69, 246-252.

Dreyer, K. E., \& Renner, P. Self-punitive behaviormasochism or confusion? Psychological Review, 1971, 78, 333-337.

MeLVIN, K. B. Vicious cycle behavior. In H. D. Kimmel (Ed.), Experimental psychopathology: Recent research and theory. New York: Academic Press, 1971.

(Received for publication September 6, 1978.) 